\title{
Um estudo sobre a constituição de um centro de atendimento educacional especializado: a reconfiguração da educação especial
}

Luciane Torezan Viegas*

\section{Resumo}

O presente estudo teve como objetivo compreender o processo de reconfiguração das proposiçóes que vinculam a educação especial e a educação regular dos alunos com deficiência, considerando os contextos, os espaços decisórios de uma rede municipal de ensino e o investimento em espaços alternativos - centros de atendimento - como possibilidade de apoio complementar à escolarizaçáo. Trata-se de uma pesquisa de caráter qualitativo que no plano da ação metodológica, investiu prioritariamente na análise documental e na interlocução com os atores sociais envolvidos por meio de entrevistas semiestruturadas. Essas estratégias auxiliaram nas análises das políticas públicas voltadas para a educação especial, associadas às singularidades de um contexto de rede pública municipal na regiáo metropolitana de Porto Alegre. Conclui-se que a reconfiguração da educação especial nessa rede municipal de ensino tenha se reestruturado com base na obrigatoriedade da dupla matrícula como argumento legal que impulsionou as práticas no sentido de tornar a escolarizaçáo dos alunos com deficiência obrigatória nas escolas regulares, nas classes comuns. Essa reconfiguração teve como eixo a transformação da escola especial pública municipal, que atendia alunos com deficiência, em centro de atendimento educacional especializado.

Palavras-chave: Educação especial; Centro de atendimento; Atendimento educacional especializado.

\footnotetext{
* Professora doutora do Centro Universitário Metodista (IPA), Porto Alegre, Rio Grande do Sul, Brasil.
} 


\section{A study on the establishment of an educational service center specialist: a reconfiguration of special education}

\section{Abstract}

This study aimed to understand the process of reconfiguration of the propositions that link the special education and regular education students with disabilities, considering the contexts, the decision spaces of a municipal school and investment in alternative spaces - call centers - as the possibility of additional support for schooling. This is a qualitative research study that, in terms of methodological action, invested primarily in document analysis and dialogue with social actors involved through semi -structured interviews. These strategies helped in the analysis of special education facing public policies associated with singularities of a context of public health system in the metropolitan region of Porto Alegre. We conclude that the reconfiguration of special education that municipal schools have restructured based on whether mandatory dual enrollment as a legal argument that propelled practices in making schooling compulsory for students with disabilities in regular schools, in regular classes. This reconfiguration was to axis transformation of municipal public special school that catered to students with disabilities in places of specialized educational services.

Keywords: Special education; Call center; Specialized educational services.

\section{Introdução}

O presente estudo aborda a reconfiguração, com base na legislação nacional, da educação especial em uma rede pública municipal, de um município localizado na região metropolitana de Porto Alegre/RS. Inicialmente apresenta-se breve análise do histórico da educação especial na rede municipal, abordando os contornos da constituição do atendimento educacional especializado (AEE) no municípios estudado. Objetiva-se, portanto, compreender o processo de reconfiguração das proposições que vinculam a educação especial e a educaçáo regular dos alunos com deficiência, considerando os contextos, os espaços decisórios de uma rede municipal de ensino e o investimento em espaços alternativos - centros de atendimento - como possibilidade de apoio complementar à escolarização.

A proposta é realizar uma análise da prática de uma política que foi se constituindo em âmbito nacional e se materializou, na falta de melhor termo, na reestruturação da perspectiva de atendimento local aos alunos com deficiência. Os estudos de políticas educacionais vêm se configurando no Brasil como um campo distinto e em busca de consolidação. Não se sustenta, neste texto, numa visão linear e racional do processo de elaboração e de implementaçáo de políticas, já superado por visões menos fragmentadas e mais dinâmicas de como se constituem as políticas no âmbito local municipal (MAINARDES; FERREIRA; TELLO, 2011). 
No plano de ação metodológico, realizou-se uma pesquisa de caráter qualitativo, com coleta de dados através de entrevistas semiestruturadas e realização de análise documental. Ambas as estratégias auxiliaram a pensar as políticas públicas voltadas para a educação especial, tanto no âmbito nacional quanto local, possibilitando perceber as nuances e tramas que se estabelecem na ressignificação interpretativa dos textos nacionais e na produção das políticas locais.

\section{Caracterizando a rede municipal de ensino: o atendimento educacional especializado}

$\mathrm{Na}$ década de 1970, como forma de atender aos alunos com deficiência em seu processo de escolarizaçáo, criam-se as classes especiais e, posteriormente, a única escola especial do município, mantida pela rede pública municipal. Convém referir que o município estudado manteve a escola especial e as classes especiais em escolas regulares, sendo que, conforme as políticas foram sendo publicadas (BRASIL, 2001a; BRASIL, 2001b), a fim de dar conta da oferta de espaços específicos para atendimento dos alunos com deficiência na escola regular, a rede municipal foi se organizando para receber os subsídios do Governo Federal e criar nas escolas regulares formas de atendimento às necessidades dos alunos da educação especial.

Os gestores entrevistados apontam em determinados momentos, o quanto se estudou na rede municipal a legislação que trata da educação especial (Entrevistadas 1 e 2) e destacam este aspecto como impulsionador das mudanças que aconteceram na rede desde início dos anos 2000. Na prática, a rede municipal já realizava movimentos no sentido de buscar atender às necessidades do alunado da educação especial, todavia a possibilidade de contar com recursos do Governo Federal para dar conta da demanda impulsionou mudanças e gerou açóes que se tornaram dispositivos de inclusão dos alunos com deficiência na rede regular.

Segundo a secretária de educação:

Em 2004, 2005, 2006 surgiram as salas de integração e recursos, que atendiam os alunos lá do Lampadinha, mas nesta época os alunos comęaram a procurar mais as escolas de ensino fundamental. Embora eu não estivesse na gestão, mas como professora da rede eu percebia que isto incomodava muito os pais, os professores, as familias que se assustavam com esta possibilidade. Muitas famílias tinham tido experiências com a escola regular e tinham sido experiências frustradas (Entrevistada 1).

Importante considerar este aspecto levantado na fala da secretária, pois a relação das famílias atendidas na escola especial com as escolas regulares, ao que parece, nem sempre foi tranquila. Os profissionais da escola, assim como os familiares, demonstravam certa resistência ou desconforto em relação ao fato de seus filhos e alunos serem incluídos na rede regular de ensino. $\mathrm{O}$ avanço em termos de atendimento na escola regular percebido na reconfiguração dos serviços e na forma de atendimento, paradoxalmente coexiste com as resistências de familiares, de profissionais e dos próprios alunos, alicerçados em argumentos como: a questão da segurança, a falta de preparo da escola regular, necessidade de formação docente, ausência de recursos destinados à aprendizagem dos alunos com deficiência, dentre tantos outros. 
Ainda na perspectiva da reorganização dos serviços de atendimento aos alunos com deficiência, a sala de recursos, como serviço educacional especializado dirigido às pessoas com deficiência, está contemplada na Política Nacional de Educação Especial (BRASIL, 1994) e nos "Subsídios para Organização e Funcionamento de Serviços de Educação Especial” (BRASIL, 1995), definida como uma sala "afastada de estímulos exteriores que prejudiquem a concentraçáo do educando [...] com o mesmo equipamento utilizado na sala de aula comum, ressaltando-se a necessidade de recursos audiovisuais" (BRASIL, 1994, p. 37). Além disso, "o atendimento na sala de recursos exige o planejamento conjunto dos professores da sala de recursos e da classe comum, a avaliação periódica e sistemática da programação elaborada para o educando" (BRASIL, 1994, p. 38). Assim, a proposta da época procurava garantir que a sala de recursos cumprisse seu papel como ambiente propício à aprendizagem dos alunos com deficiência, manifestando rigor quanto ao local, com condiçóes que garantissem a concentraçáo dos alunos, e quanto à proposta de intervençâo pedagógica, construída em parceria com o professor da classe comum.

Da mesma forma, o Conselho Estadual de Educação do Estado do Rio Grande do Sul (CEED) define a proposta para o trabalho desenvolvido nas salas da seguinte maneira:

\begin{abstract}
A sala de recursos é o serviço, de natureza pedagógica, conduzido por professor especializado, que suplementa (no caso dos superdotados) e complementa (para os demais alunos) o atendimento educacional realizado em classes comuns. Esse serviço deve ser realizado em local dotado de equipamentos e recursos pedagógicos adequados às necessidades educacionais especiais dos alunos, podendo estender-se a alunos de escolas próximas, nas quais náo exista esse atendimento. Pode ser realizado individualmente ou em pequenos grupos, para alunos que apresentem necessidades educacionais especiais semelhantes, em horário diferente daquele em que frequentam a classe comum. (RIO GRANDE DO SUL, 2006, art. 15).
\end{abstract}

Como se pode perceber, as linhas que organizam o serviço estão presentes de forma sucinta nesta definição, considerando-se a ênfase na natureza pedagógica do atendimento prestado ao aluno. Também a formação do professor para atuar neste espaço é enfatizada e tem sido objeto de diferentes estudos relativos à necessária capacitação dos profissionais das salas de recursos e das classes comuns que atendem alunos da educação especial (TEZZARI, 2002; PRIETO; SOUZA, 2007; TEZZARI; BAPTISTA, 2002). Além disso, a referência aos recursos necessários e à forma de atendimento (individual ou em grupos) remete aos subsídios com os quais o professor da sala poderá contar na tarefa de realizar açóes voltadas para o ensino dos alunos com deficiência.

Baptista (2011) realiza estudo e apresenta reflexôes acerca da açâo pedagógica e dos serviços educacionais especializados dirigidos às pessoas com deficiência. Considerando o atual contexto, em que as políticas indicam a inclusão escolar como uma diretriz, o autor analisa as características e desafios que marcam a oferta dos serviços especializados, bem como a açáo dos profissionais que atuam nesses espaços. Con- 
clui que os estudos que analisam as salas de recursos são exíguos e relaciona o fato à restrição da existência das salas a alguns contextos. Segundo autor, "o histórico de investimento em classes especiais e em escolas especiais reduzia a suposta necessidade da sala de recursos". Também, o mesmo coloca em evidência que "a sala de recursos tem sido destacada como o espaço prioritário para a ação do educador especializado em educação especial" (BAPTISTA, 2011, p. 70).

Considerar essas afirmaçóes no contexto da rede pública municipal faz sentido, na medida em que a rede manteve, desde a década de 1970, tanto classes quanto escolas especiais, e inicia um trabalho voltado para o suporte das escolas regulares para atenderem alunos com deficiência, quando recebem recursos do Governo Federal, de 2007 em diante.

No ano de 2008, a rede municipal de ensino contava com quatro Salas de Integração e Recursos (SIR) e, em 2013, esse número foi ampliado para 12 Salas de Recursos Multifuncionais (SRM), atendendo aos alunos por região. A proposta do Serviço de Atendimento Educacional Especializado (SAEE) também envolvia a formaçãa continuada de professores. Nesse período, amplia-se a formação, que deixa de ser dirigida exclusivamente ao docente que trabalhava diretamente com o aluno, e passa a abranger todos os professores, equipes pedagógicas e funcionários atuantes em cada uma das escolas regulares.

Segundo a assessora de educação especial

o pessoal ainda resiste muito, discute muito, mas as pessoas antigas são muito arraigadas, são muito fechadas na sua formação, inclusive discriminam quem vem com uma formaçấo mais ampliada, pois o consideram especialista em nada (Entrevistada 2).

Por trás desta concepção está a ideia de que:

o profissional precisa saber bastante de deficiência para trabalhar com o deficiente (Entrevistada 2).

Assim, a leitura que se poderia fazer deste ponto é que a proposta da SIR era voltada para a deficiência especificamente, e a proposta da SRM se amplia, considerando as condições de aprendizagem como foco.

Ainda essa fala retrata o quanto há de diferenciação conceitual no que diz respeito à proposta da escola especial e seus atendimentos especializados por deficiência e a proposta de educação inclusiva, que inclui o aluno e impulsiona a escola a buscar formas de ensinar a todo alunado. Nesse sentido, observa-se uma reconfiguração significativa, pois a escolarização dos alunos com deficiência, que é vista como exclusivamente substitutiva por um período histórico expressivo, parece ocupar o lugar complementar ou suplementar no processo de educação desses alunos, que se constrói na escola regular. Gradativamente, os alunos com deficiência se inserem no contexto da escola regular e impulsionam mudanças, na visão dos entrevistados, na organizaçáo pedagógica, metodológica, curricular, na formação docente e na configuração dos serviços de atendimento educacional especializado. 
No que diz respeito à viabilidade de oferta do AEE, de 2007 em diante, o município adere ao Programa de Implantação de Salas de Recursos Multifuncionais ${ }^{1}$, o que faz com que haja uma significativa ampliação do número de salas, chegando, em 2012, com 12 salas em escolas regulares, por zoneamento, e duas salas em escolas municipais de educação infantil. Muda-se a perspectiva do atendimento ao alunado com a adesão ao Programa, visto que as salas de recursos atendiam os alunos por deficiência e as salas multifuncionais atendem todos os alunos, independente da deficiência, utilizando recursos e métodos adequados às suas necessidades.

Sintonizada com a Política Nacional de Educação Especial (BRASIL, 2008), a Rede Municipal de Educação segue com o Plano de Açôes Articuladas (PAR), no intuito de conseguir implantar as Salas de Recursos Multifuncionais nas 20 escolas de Ensino Fundamental da rede, pois, em 2013, havia em torno de 300 alunos com deficiência, frequentando-as nas escolas regulares.

No que se refere ao encaminhamento dos alunos com deficiência para as SRM, há um fluxo previsto na rede, pois, segundo a assessora de educação especial,

quando um aluno chega com um laudo, com um diagnóstico, um indicativo já formalizado, as professoras das turmas comuns fazem um pequeno relatório, encaminhamno para a assessoria, que encaixa na planilha do AEE (Entrevistada 2).

Cabe referir que há uma grande diversidade de deficiências identificadas pelas profissionais que atendem no AEE: deficiência intelectual, deficiência múltipla, transtorno de déficit de atenção, transtorno de conduta e autismo. Quando não há laudo clínico, o aluno fica em observação até se fechar um laudo e também se realiza uma avaliação pedagógica. Tanto a professora que atua na Sala de Recursos Multifuncionais quanto a professora que atua na turma comum trabalham juntas para a configuraçáo deste laudo que irá garantir o atendimento da criança pelo AEE.

Bridi (2011), em estudo realizado na rede pública municipal de Santa Maria/RS, sobre os processos de identificação e diagnóstico dos alunos com deficiência mental, no contexto do AEE, refere que, mesmo quando realizado por profissionais da área da educaçáo, o diagnóstico tende a ser pautado por premissas do campo clínico. Destaca também a emergência de posiçôes diferenciadas e a coexistência de distintas tendências de compreensão do processo diagnóstico presentes nos pareceres pedagógicos. Considera-se importante refletir sobre este ponto, visto que ele revela a concepçáo implícita no olhar profissional sobre o aluno e também dele dependem inúmeras formas de configurar o AEE para o mesmo.

$\mathrm{Na}$ rede pública municipal estudada, independe se o aluno é avaliado clinicamente ou de forma pedagógica, ou ambas, para encaminhamento ao atendimento na Sala de Recursos Multifuncionais. O procedimento padrão incluía indicação de horários no turno oposto ao da turma regular que frequenta, mas registra-se também, em alguns casos, o atendimento no mesmo turno, em função de dificuldades da família em se comprometer com a presença do aluno nos dias e horários definidos. Essa estratégia é uma maneira de possibilitar o atendimento educacional especializado para os alunos com deficiência que necessitem desse acompanhamento. 
Outro suporte importante que existe na rede, para dar conta das demandas da educação especial, é a existência de educadores sociais. Em torno de 15 profissionais concursados atendem às demandas de cuidado com saúde e autocuidado de alunos com comprometimentos motores, indicados pela assessoria, quer estejam na escola regular, sendo atendidos pela SRM quer estejam no Centro. Segundo a diretora pedagógica do Centro,

naquela época, na Constituinte ${ }^{2}$, se pensou que poderia ser um estagiário, um monitor, professor auxiliar ou dupla docência. Foi feito um estudo financeiro e se percebeu que não tinha como, pois geraria um custo muito alto para o município (Entrevistada 3).

Então, já em 2005, o município fez concurso na área de Assistência Social para o cargo de educador social. O perfil desejado na época indicava a necessidade do candidato ter Ensino Médio completo, sem formação na área da Educação. O cargo previa que esses educadores sociais atuassem nos abrigos e em projetos sociais, porém foram designados também para atuar nas escolas com alunos que exigissem maior cuidado relativo à locomoção e cuidados específicos de higiene, alimentaçáo etc.

O entendimento da assessora de educaçáo especial (Entrevistada 2), em relação a esse assunto, é de que, como estes profissionais não estão ligados diretamente à área da educação, precisariam receber formação continuada a fim de qualificar a ação junto aos alunos e definir seu papel nas escolas. Foi preciso, segundo a entrevistada, trabalhar primeiramente a identidade deste grupo, uma vez que alguns já eram graduados em pedagogia, serviço social, direito, havendo também estudante de psicologia. Relata a entrevistada que, no final de 2011, foi feito o primeiro encontro de formação com esse grupo, organizado pela assessoria, em que foi feito um levantamento prévio do que esses profissionais gostariam de estudar para auxiliar no exercício dessa função. De acordo com a assessora,

dessa forma eles sugeriram vários temas, não fugindo do cuidado, mas avançando para o pedagógico. E deu muito certo, um grupo que deu muito certo (Entrevistada 2).

Considerando a perspectiva de continuidade dos estudos dos alunos com deficiência, desligados do Ensino Fundamental, a assessora entrevistada também sinaliza que uma turma de Educação de Jovens e Adultos do município conta com uma SRM que atende a 12 alunos da educação especial, alguns oriundos da escola especial. Os dados do INEP mostram que em 2012 foram indicados 17 alunos e em 2013 apenas 13 alunos nesta condição, recebendo apoio da SRM nas turmas de EJA3.

A ênfase, portanto, do Atendimento Educacional Especializado oferecido na rede municipal é a oferta no contraturno, em salas de recursos multifuncionais, na própria escola, ou em outra escola nas proximidades ou no centro de atendimento educacional especializado, sendo implementado por professores e profissionais com formaçáo especializada, "de acordo com plano de atendimento aos alunos, que identifique suas necessidades educacionais específicas, defina os recursos necessários e as atividades a serem desenvolvidas" (CACHOEIRINHA, 2013, art. 9, Parágrafo Único). 
Percebe-se ao longo da pesquisa realizada o quanto as mudanças referentes ao tipo de atendimento ofertado aos alunos com deficiência vão se configurando a partir de 2007. Inicialmente, a escolarização dos alunos com deficiência se centra, na maior parte dos casos, na escola especial, mas gradativamente as SRM vão se constituindo na rede municipal, substituindo as classes especiais ainda existentes nas escolas regulares. Ampliam-se as salas advindas do Programa de Implantação das SRM e os alunos com deficiência, em sua maioria, passam a se matricular nas escolas regulares, compondo as classes comuns e recebendo AEE no contraturno. Tal configuração acompanha as discussóes ocorridas na rede acerca da necessária mudança na constituiçáo da escola especial, em pauta desde o ano de 2006, conforme relato da secretária de educação (Entrevistada 1). Portanto, a educação especial passa a ser compreendida como complementar ou suplementar, reorganizando-se para atender às necessidades dos alunos com deficiência sob a forma de atendimento educacional especializado oferecido nas SRM.

\section{A constituição de um centro de atendimento educacional especializado na rede pública municipal}

Procura-se ao longo do texto abordar a constituição do atendimento às pessoas com deficiência na rede municipal de educaçáo e relacionando as propostas para este atendimento, configuradas na rede, com as definidas na legislação federal e estadual, como também nas políticas voltadas para a educação inclusiva, em especial a Política Nacional de Educação Especial na perspectiva da Educação Inclusiva (BRASIL, 2008), documento considerado impulsionador das mudanças propostas na rede municipal.

Contudo, a considerar o tratado até este momento, é pertinente questionar: o que fez com que se encerrassem as atividades da escola especial e se constituísse um centro

Segundo a assessora técnica do Conselho Municipal de Educação,

é a morte de uma instituição, de alguma coisa para criar algo novo e dai se pensou: mas como podemos fazer? Ah, um fórum. Vamos chamar várias representatividades para pensar juntos, para poder estar dialogando (Entrevistada 4).

Assim, no final do ano de 2010, constituiu-se um grupo, por solicitação da mantenedora ${ }^{4}$, liderado com profissionais da escola especial, com o intuito de dedicar horas de estudo e debate sobre o atendimento educacional especializado no município. Pais, professores, funcionários, gestores, diretores da escola especial, de escolas regulares e de educação infantil debateram o tema, no que se constituiu como um Fórum de Discussão sobre o futuro da escola especial. Logo, o debate centrou-se nas reflexóes e propostas de alternativas para transformar a escola especial em centro de atendimento educacional especializado (VASQUES e MARQUES, 2012).

O Fórum de Discussão manteve uma sistemática de encontros entre os anos de 2010 e 2011 com uma participação variada, segundo as atas dos encontros. Várias questôes foram tratadas nesses momentos, que também foram espaços para que os 
integrantes pudessem expressar suas dúvidas, medos, críticas e dialogar sobre o significado de tal proposta para o município.

Importante destacar, nesse caso, o papel dos gestores na condução do processo, uma vez que as decisôes referentes aos rumos da educação especial aconteceram, ao que tudo indica, com intensa participação das pessoas envolvidas na gestão. Durante a realização da pesquisa fica claro o quanto as concepçóes dos gestores influenciaram nas decisóes e encaminhamentos realizados em determinados momentos.

Independentemente dos motivos legais informados, das concepçôes expressas nas políticas atuais no que se refere à educação inclusiva, da mobilização da gestáo municipal para que houvesse uma ressignificação do atendimento oferecido aos alunos com deficiência na rede, o fórum também deu visibilidade às resistências, às concepçôes diferenciadas, favoráveis à manutenção da escola especial e dos espaços especializados como forma prioritária de atendimento a este público-alvo.

No que se refere aos motivos alegados para cessar as atividades da escola especial e criar um centro de atendimento educacional especializado, a dimensão legal parece ter sido parte da estratégia de convencimento por meio do diálogo utilizada pelos gestores da rede municipal a fim de lidarem com as famílias neste processo.

Durante o ano de 2011, portanto, houve toda uma movimentação na escola especial para o encerramento das atividades. A Secretaria Municipal deslocou duas profissionais, uma psicóloga e uma assistente social, para começarem a dar suporte para o grupo, realizando entrevistas com as famílias e entrevistas com a equipe.

Considera-se importante destacar que o sentimento das pessoas envolvidas no que se refere a uma mudança desta natureza precisa ser considerado, na medida em que os mesmos impulsionam práticas. Ao falar de luto, é preciso compreender a extensão de um trabalho de 34 anos desenvolvido em uma determinada perspectiva e que se rompe em determinado momento para ser ressignificado. $O$ tempo das pessoas para dar conta de mudanças desta natureza também precisa ser considerado. Em relação a isso, manifesta-se a presidente do CME:

A equipe diretiva também, até o final, assim, parece que não estava acreditando que isto ia ser possivel. Quando lá em dezembro, a secretária bateu o martelo, não, então depois do próximo ano a gente vai organizando, vamos fazer (Entrevistada 5).

Desta forma, ao final de 2010, após inúmeros encontros do Fórum de Discussão, foi tomada a decisão de preparar no ano seguinte a rede para a cessação das atividades da escola especial e para a criaçáo do centro municipal de atendimento educacional especializado.

O município estudado é exemplo desta situação, pois no ano de 2011 atendia aproximadamente 300 alunos em SRM e 86 alunos eram atendidos na escola especial quando foi descredenciada. Desses 86 , apenas quinze permaneceram com indicação de matrícula no Centro para o ano seguinte (CACHOEIRINHA, 2011). Os demais alunos da escola especial, conforme orientação da Secretaria, foram matriculados nas escolas regulares e foram avaliados quanto à permanência na SRM ou encaminha- 
mento para o Centro. Muitos receberam indicação de matrícula também no Centro, mantendo o vínculo da mesma forma neste espaço.

Quando analisamos o contexto da educação especial na rede municipal estudada, destacamos que, no momento em que se decidiu por cessar as atividades da escola especial e criar o Centro, houve contrariedades, particularmente de professores que estavam há muitos anos na escola especial e que não concordavam com a mudança. Segundo a secretária de educação, é importante destacar que

se os professores querem seguir a lógica da escola, precisam ir para a escola, pois o Centro precisa ser um lugar em que efetivamente as pessoas desejem estar, porque o lugar do professor, independente de qualquer coisa é na escola (Entrevistada 1).

No que se refere à reconfiguração da educação especial observada na rede municipal, destacam-se alguns pontos como elementos constitutivos destas modificaçóes. $\mathrm{O}$ atendimento educacional especializado passa a ser complementar ou suplementar e perde, efetivamente, o caráter substitutivo ao se configurar como ofertado nas Salas de Recursos Multifuncionais e no Centro para alunos com deficiência matriculados na rede regular de ensino. A dupla matrícula, utilizada como referência legal para o convencimento da comunidade através do diálogo manifesta-se como eixo importante no entendimento dessa nova configuraçáo.

Da mesma forma, elementos como o papel da família na manutenção de seus filhos na escola regular e no Centro, ou seja, a constituição dos direitos dos alunos e dos deveres dos responsáveis, pais e profissionais, toma vulto na medida em que alguns alunos com deficiência mantêm a frequência no Centro, mas não na escola regular. Muda o perfil do alunado do Centro e a construçáo da proposta pedagógica voltada para os alunos com deficiência atendidos nesta modalidade evidencia a necessidade de investir em formação continuada para os profissionais da rede que atuam na educação especial. Observam-se inúmeros pontos de tensão e perspectivas de novas possibilidades com a constituição do Centro, a complexidade se manifesta nos desafios e no processo que envolve inúmeros atores e se (re)configura na prática, a partir da ressignificação do já existente e da configuração do novo.

\section{Conclusões}

Observa-se, no que diz respeito à sintonia com as políticas, que há diferentes momentos em que este alinhamento acontece de modo explícito, relatado pelos entrevistados, que afirmam terem se pautado nos documentos que norteiam a Política Nacional de Educação Especial (BRASIL, 2008) para reconfigurar o atendimento educacional especializado ofertado aos alunos com deficiência incluídos na rede regular de ensino. No âmbito do presente estudo, essa sintonia se expressa na redefinição dos espaços de atendimento, assim como na finalidade das açốes que representam a educação especial naquele contexto: a transformação de uma escola especial em um centro de atendimento educacional especializado.

Na prática local, configuram-se ênfases a alguns aspectos referentes a pontos considerados significativos para os gestores e a rede municipal de ensino, como a 
matrícula dos alunos com deficiência na rede regular. O contexto legal nacional foi evocado para que se procedesse à argumentação com as famílias dos alunos da escola especial e também com os professores a fim de justificar o encerramento das atividades daquela escola e a criação do Centro. A mudança de rumo na configuração da educação especial acontece a partir do momento em que se decide pela dupla matrícula, na escola regular e no AEE, nas SRM ou no Centro, tornando o atendimento especializado complementar ou suplementar ao ensino regular e não mais substitutivo.

Quando se constituiu o Fórum de Discussão no município para tratar do Atendimento Educacional Especializado, a possibilidade de cessar as atividades da escola especial e criar o Centro já estava dada. A decisão dos gestores referendou um momento de reestruturação da educação especial na rede, pois a busca por dispositivos que pudessem viabilizar a permanência dos alunos com deficiência nas escolas regulares era emergente. As Salas de Recursos Multifuncionais e o Centro, de certa forma, conseguem ou são capazes de manter os alunos nas classes comuns, mas já há indícios da necessidade de suprir com recursos/equipamentos/estratégias o ensino comum. Entende-se que esta seja uma possibilidade futura para a reconfiguração do AEE na rede municipal, uma vez que a aprendizagem dos alunos com deficiência deveria ter como espaço privilegiado as classes comuns, na rede regular de ensino. $\mathrm{O}$ fato de se ofertar no contraturno o AEE nas salas e no Centro pode indicar que a aprendizagem dos alunos com deficiência estaria condicionada a ocorrer prioritariamente nestes espaços, o que de certa forma é coerente, em função da existência de recursos e estratégias supostamente adequadas às necessidades de ensino para esses alunos.

Portanto, entende-se que é no momento da aula na classe comum que estes recursos e estratégias precisam estar disponíveis, de forma a viabilizar a aprendizagem dos alunos com deficiência. Ainda é uma utopia, visto que perpassa as condiçóes financeiras e também as barreiras impostas pela concepçáo dos profissionais que atuam com estes alunos, mas fica o registro de uma possibilidade. O que justificaria o encaminhamento do aluno com deficiência para o Centro? A resposta poderia representar a busca por um espaço que não existe na rede, que nem os laboratórios de aprendizagem nem as Salas de Recursos Multifuncionais poderiam oferecer.

\section{Referências:}

BAPTISTA, C. R. Ação pedagógica e Educação especial: a sala de recursos como prioridade na oferta de serviços especializados. Revista Brasileira de Educaçáo Especial, Marília, v. 17, p. 59-76, maio/ago. 2011.

BRASIL. Ministério da Educação. Política nacional para a educação especial na perspectiva da educação inclusiva. Brasília: MEC, 2008.

Conselho Nacional de Educação - Câmara de Educação Básica. Parecer CNE/CEB no 17, de 03 de julho de 2001. Diretrizes Nacionais para a Educação Especial na Educação Básica. 2001a. Diário Oficial [da] República Federativa do Brasil, Brasília, DF, 17 ago. 2001. Seção 1, p. 46.

Conselho Nacional de Educação - Câmara de Educação Básica. . Resolução CNE/CEB no 2, de 11 de setembro de 2001. Institui Diretrizes Nacionais para Educação Especial na Educação Básica. 2001b. Disponível em: < http://portal.mec.gov.br/cne/arquivos/pdf/CEB0201.pdf>. Acesso em: 16 nov. 2013.

Secretaria de Educação Especial. Subsídios para organização e funcionamento de serviços de Educação Especial: área de deficiência mental. Ministério da Educação e do Desporto, Secretaria de Educação Especial. Brasília: MEC/SEESP, 1995. 
Ministério da Educação e do Desporto/SEESP. Política nacional de educação especial. Brasília: Secretaria de Educação Especial, 1994.

BRIDI, F. R. Os processos de identificaçáo e diagnóstico: os alunos com deficiência mental no contexto do Atendimento Educacional Especializado. 2011. 210 fls. Tese (Doutorado em Educação). Programa de Pós-Graduaçâo em Educação. Universidade Federal do Rio Grande do Sul, Porto Alegre, 2011.

CACHOEIRINHA. Conselho Municipal de Educação de Cachoerinha (CME). Resolução CME no 19, de 19 de março de 2013. Regulamenta a Educaçăo Especial na perspectiva da Escola Inclusiva, na Educação Infantil, Ensino Fundamental e Modalidade Educação de Jovens e Adultos do Município de Cachoeirinha e dá outras providências. Cachoeirinha: Conselho Municipal de Educação, 2013.

Conselho Municipal de Educação de Cachoeirinha (CME). Parecer no 23, de 18 de novembro de 2011. Cessação do efeito da credencial de autorização para funcionamento da EMEF, modalidade educaçáa especial, Lampadinha, cancelando o credenciamento para oferta. Cachoeirinha: Conselho Municipal de Educaçáo, 2011.

. Secretaria Municipal de Educação (SMEd). II Constituinte Escolar. Cachoeirinha: Secretaria Municipal de Educação, 2010.

MAINARDES, J.; FERREIRA, M. S.; TELLO, C. Análise de políticas: fundamentos e principais debates teóricos-metodológicos. In: BALL, S.; MAINARDES, J. (Orgs.). Políticas educacionais: questōes e dilemas. São Paulo: Cortes, 2011.

PRIETO, R.; SOUZA, S. Educação especial: o atendimento em salas de recursos na rede municipal de São Paulo. Educação Revista do Centro de Educaçáo, Santa Maria, v. 32, n. 2, p. 375-396, 2007.

RIO GRANDE DO SUL. Ministério Público do Estado do Rio Grande do Sul. Parecer CEED n 56, de 2006. Orienta a implementação das normas que regulamentam a Educação Especial no Sistema Estadual de Ensino do Rio Grande do Sul. Disponível em: <http://www.mprs.mp.br/infancia/legislacao/id3249.htm>. Acesso em: 16 nov. 2013.

TEZZARI, M. L. “A SIR chegou ...” Sala de Integração e Recursos e a Inclusão na Rede Municipal de Ensino em Porto Alegre. 2002. 182f. Dissertação (Mestrado em Educaçáo) - Faculdade de Educação, Programa de PósGraduaçáo em Educaçáo. Universidade Federal do Rio Grande do Sul, Porto Alegre, 2002.

TEZZARI, M. L.; BAPTISTA, C. R. Vamos brincar de Giovani? A integraçâo escolar e o desafio da psicose. In: BAPTISTA, C. R.; BOSA, C. (Orgs.). Autismo e educação: reflexôes e propostas de intervenção. Porto Alegre: Artmed, 2002, p.145-156.

VASQUES, C.; MARQUES, A. Da escola especial ao centro de atendimento educacional especializado: olhares em movimento. Poiésis, UNISUL, Tubarăo, v. 6, n.10, p. 411-422, jul./dez. 2012.

\section{Notas}

${ }^{1}$ Portaria Normativa no 13, de 24 de abril de 2007. Dispóe sobre a criação do "Programa de Implantação de Salas de Recursos Multifuncionais". MINISTÉRIO DA EDUCAÇÃO. Programa de Implantaçáo das Salas de Recursos Multifuncionais, 2007. Fonte: <http://portal.mec.gov.br/dmdocuments/salasmultifuncionais.pdf>. Acesso em $15 / 11 / 2013$.

${ }^{2}$ I Congresso da Constituinte Escolar de Cachoeirinha, realizado em 2001, aprovou cento e cinco resoluçóes que subsidiaram os planejamentos, documentos e açóes da Secretaria Municipal de Educaçáo, do Conselho Municipal de Educação e das escolas municipais (CACHOERINHA, 2010).

${ }^{3}$ Tabela dos Resultados finais do Censo Escolar 2012 e Tabela dos Resultados Preliminares do Censo Escolar 2013 (MEC/INEP).

${ }^{4} \mathrm{O}$ termo mantenedora refere-se à Secretaria Municipal de Educação.

\section{Correspondência}

Luciane Torezan Viegas - Centro Universitário Metodista, IPA. Rua Joaquim Pedro Salgado, 80. Rio Branco, CEP: 90420-060 - Porto Alegre, Rio Grande do Sul - Brasil.

E-mail: luciane.viegas@metodistadosul.edu.br

Recebido em 20 de outubro de 2014

Aprovado em 03 de novembro de 2015

Revista Educação Especial | v. 29 | n. 54 | p. 109-120 | jan./abr. 2016 